\title{
The recovery of rare earth metals from WEEE leaching solution via liquid-liquid extraction
}

\author{
Talebi A. ${ }^{1,}{ }^{*}$, Marra A. ${ }^{2}$, Cesaro A. ${ }^{2}$, Belgiorno V. ${ }^{2}$ and Norli I. ${ }^{1,}{ }^{*}$ \\ ${ }^{1}$ School of Industrial Technology, Universiti Sains Malaysia, 11800 Minden, Penang, Malaysia \\ ${ }^{2}$ SEED - Sanitary Environmental Engineering Division, Department of Civil Engineering, University of Salerno, 84084 Fisciano, Italy \\ Received: 27/02/2018, Accepted: 14/04/2018, Available online: 26/09/2018 \\ *to whom all correspondence should be addressed: e-mail: amirtalebi@usm.my,norlii@usm.my \\ https://doi.org/10.30955/gnj.002646
}

\begin{abstract}
The recovery of rare earth metals (REMs) from end-of-life products, such as Waste Electrical and Electronic Equipment (WEEE), is drawing great attention as an attractive strategy for promoting the sustainable development. The hydrometallurgical technique of solvent extraction has been reported to be one of the most interesting method to recover REMs. However, when applied to WEEE, this process is challenged by the heterogeneous composition of electronic waste, completely different from other solid matrices, and it still has much rooms of improvements.
\end{abstract}

This study investigated the extraction, stripping and recovery of REMs from a WEEE leaching solution using Versatic 10 as carrier in the organic phase and oxalic acid as stripping agent. A factorial design was carried out to evaluate the simultaneous effects of factors as the feed phase $\mathrm{pH}$ and the concentrations of both extractant and organic phase modifier in the extraction process. Cerium, lanthanum and yttrium were extracted at high percentages using $200 \mathrm{mM}$ of Versatic 10, loaded by $100 \mathrm{mM}$ of TBP in kerosene at $\mathrm{pH}$ 7. Moreover, $750 \mathrm{mM}$ of oxalic acid successfully stripped and recovered 7.63 and $13.82 \mathrm{mg} / \mathrm{kg}$ of lanthanum and yttrium, respectively.

Keywords: Solvent extraction, critical metals, versatic 10, couple countered, oxalic acid, hydrometallurgy.

\section{Introduction}

Rare earth metals (REMs) are vital raw materials for developing renewable energy technologies and essential elements for modern high-tech products. Global REM demand is knocked to grow at an annual rate of $5 \%$ by 2020. This increasing demand will require a steady supply base of REMs in the long run (Tanushree et al., 2016). In this view, there is an urgent need to develop efficient REM reclaiming techniques from end-of-life products or secondary sources as well as replace these critical elements with possible substitutes (Alonso et al., 2012).

Waste electrical and electronic equipment (WEEE) is considered as a noticeable source of various elements, including REMs, whose recycling would have an enormous impact on the environmental protection policies and approaches (Buchert et al., 2012; Binnemans et al., 2013; Innocenzi Baldé et al., 2014; Baldé et al., 2015; Dupont and Binnemans, 2015; Savvilotidou et al., 2015; Diaz et al., 2016). However, in EU countries the total amount of the recycled WEEE is still low, owing to insufficient collection rates, legal and illegal exports and poor recovery rates of end-refining processes with particular regard to some metals as REMs (Bakas et al., 2014).

Numerous researchers have been trying to work out an efficient way to enhance REMs recovery from WEEE. For this purpose, hydrometallurgy, involving metals leaching into solution followed by their separation, is the favourite route for REE recovery from end-of-life products (Tunsu et al., 2015). Although this process can be successfully applied for extracting different metals, the researchers are still studying the most efficient and simultaneously environmentally friendlier methods to recover these elements from WEEE.

Solvent extraction or liquid-liquid extraction (LLE) is being widely explored in various fields such as chemistry (organic, inorganic and analytical), biotechnology, biomedical technology and wastewater treatment (Muthuraman et al., 2009; Singh et al., 2011; Talebi et al., 2012). This technique can be applied for different purposes, including the selective separation and recovery of heavy metals, separation of aromatics from hydrocarbons, antibiotics purification, protein extraction using aqueous two-phase systems, dyes and pigments removal, metallurgical purifications (Chang et al., 2011).

In conventional systems for aqueous solution treatment, the recovery of metals is customarily carried out in a separate unit by elution with suitable reagents, occurring in additional cost (Kurniawan, 2006). Conversely, in liquid membrane (LM) systems the extraction and the recovery of the separated species can be combined in one stage. Hence, liquid membranes are more cost-effective and environmentally friendlier than other conventional techniques because they need lower volumes of organic reagents (Keith et al., 2007; Armenta et al., 2008; León and Guzmán, 2010). 
The LLE is considered as the fundamental step for the LM technique and it has been investigated for REMs removal from industrial wastewaters (Harris and Tompkins, 1947; Bunus et al., 1994; Preston et al., 1996; Lee et al., 2009; Tunsu and Retegan, 2016) and for REM ions separation in ore processing and secondary sources (Tunsu et al., 2016) in order to explore the potential scale up to LM systems.

In this framework, this study aims to evaluate the application of LLE for the recovery of REMs from a WEEE leaching solution. In this regard, Versatic 10 was tested as a carrier in the organic phase. The effect on REM extraction of parameters such as $\mathrm{pH}$, carrier and phase modifier concentrations was investigated. Furthermore, the effectiveness of the stripping and recovery of the targeted metals from the loaded organic phase using oxalic acid was examined.

\section{Material and methods}

\subsection{Leaching feed solution}

The aqueous feed solution for the LLE experiments was obtained from a leaching process involving WEEE shredding dust as solid source. The material characterization of this fraction is described in our previous studies (Marra et al., 2018).

The leaching process was performed immersing $20 \mathrm{gr}$ of WEEE shredding dust in a solution containing $160 \mathrm{~mL}$ of $2 \mathrm{M} \mathrm{H}_{2} \mathrm{SO}_{4}$ and $40 \mathrm{~mL} \mathrm{H}_{2} \mathrm{O}_{2}$. The solution was kept stirred at $150 \mathrm{rpm}$ for 3 hours using a jar test machine. The leachate was then filtered and the resulting solution was further used for the LLE procedure. The concentration of selected REMs, namely Cerium (Ce), Lanthanum (La) and Yttrium (Y), in the leaching solution is reported in Table 1.

Table 1. Concentration of REMs in the WEEE leaching solution

\begin{tabular}{cc}
\hline Metal & Concentration $(\mathrm{mg} / \mathrm{L})$ \\
\hline $\mathrm{Ce}$ & $5.2 \pm 0.15$ \\
\hline $\mathrm{La}$ & $4.4 \pm 0.13$ \\
\hline $\mathrm{Y}$ & $5.2 \pm 0.15$ \\
\hline
\end{tabular}

\subsection{LLE experiments}

The LLE procedure included an extraction step followed by a stripping phase.

Versatic acid 10 (V10, purity $\geq 98 \%$ ) and tributyl phosphate (TBP, purity $\geq 99 \%$ ), both supplied by SIGMA-Aldrich, were used to prepare the organic phase: the former was employed as a carrier and the latter as phase modifier. Kerosene, supplied by Honeywell, was used as diluent.

The prepared organic phase was mixed with the WEEE leaching solution at 1:1 ratio in a conical flask, which was kept shaken by a magnetic stirrer. After two hours stirring, samples were taken from the aqueous phase, and the concentration of the metals under investigation was determined. An extraction run in which the organic phase contained neither carrier nor phase modifier was also carried out as a control experiment.

A factorial design was performed to define the optimal experimental conditions regarding $\mathrm{pH}$, carrier and phase modifier concentrations for obtaining the highest metal extractions. These factors were assumed to vary between the levels reported in Table 2. A 13-run factorial design of experiments was proposed, including also central points.

$\mathrm{pH}$ was adjusted using $\mathrm{HCl}$ and $\mathrm{NH}_{4} \mathrm{OH}$.

Table 2. Factors and levels of the experimental design

\begin{tabular}{cccc}
\hline \multirow{2}{*}{ Factors } & \multicolumn{3}{c}{ Levels } \\
\cline { 2 - 4 } & Low (-) & Medium (0) & High (+) \\
\hline $\mathrm{pH}$ & 5.0 & 6.0 & 7.0 \\
\hline $\begin{array}{c}\mathrm{V} 10 \text { concentration } \\
\text { (mM) }\end{array}$ & 75.0 & 137.5 & 200.0 \\
\hline $\begin{array}{c}\text { TBP concentration } \\
\text { (mM) }\end{array}$ & 50.0 & 100.0 & 150.0 \\
\hline
\end{tabular}

The metal-loaded organic phase, obtained after the extraction process, was used for the further stripping studies. In this stage, $750 \mathrm{mM}$ oxalic acid $\left(\mathrm{C}_{2} \mathrm{H}_{2} \mathrm{O}_{4}\right)$ was tested as stripping agent using an organic to stripping volume ratio of 0.5 .

The white precipitate resulting from 2 hours stripping was then collected and a mineral phase analysis was conducted using the X-ray diffraction (XRD, Bruker D8 advance), with the following conditions: $\mathrm{Cu} K \alpha$ radiation, $35 \mathrm{keV}$ accelerating voltage, $40 \mathrm{~mA}$ current, $10-80^{\circ}$ scanning range, $0.5 \mathrm{~s} / \mathrm{step}\left(0.0296^{\circ} / \mathrm{step}\right)$ scan speed. The white precipitate was, moreover, calcinated in a furnace for one hour and analysed for its metal content after acid digestion.

\subsection{Analytical methods}

The metal analyses were performed by means of the inductively coupled plasma optical emission spectroscopy (ICP-OES, Thermo iCap 6000 series).

During each extraction experiment, samples were taken from the aqueous phase, filtered, adequately diluted and analysed for the selected REM concentrations.

The extraction efficiency (E\%) of the metal was, thus, calculated according to the following equation:

$$
\mathrm{E} \%=\left(\left[\mathrm{M}_{\mathrm{aq}, \mathrm{in}}^{2+}\right]-\left[\mathrm{M}_{\mathrm{aq}}^{2+}\right]\right) /\left[\mathrm{M}_{\mathrm{aq}, \text { ini }}^{2+}\right] \times 100
$$

where $\left[\mathrm{M}_{\mathrm{aq}, \mathrm{in}}^{2+}\right]$ denotes the initial concentration of the metal ion in the aqueous solution $(\mathrm{mg} / \mathrm{L})$ and $\left[\mathrm{M}_{\mathrm{aq}}^{2+}\right]$ stands for the metal concentration in the aqueous phase after the extraction process $(\mathrm{mg} / \mathrm{L})$.

\section{Results and discussion}

\subsection{Extraction studies}

Preliminary screening studies were conducted using only kerosene in the organic phase, without adding the carrier (V10) and the phase modifier (TBP). In these experiments, no metal ion extractions were observed, demonstrating that the solubility of the organic and the aqueous phase is a negligible factor in the extraction stage. The screening studies also revealed that the presence of TBP individually has not a significant effect on the extraction process. However, the TBP has an essential impact on the 
separation of the organic-aqueous mixture as it acts reducing or eliminating emulsion phase by lowering the interfacial viscosity, tension, and elasticity of the organic-aqueous interface (Marcus, 2004; Kang et al., 2006; Chagnes et al., 2012).

The surface responses of the extraction efficiencies of $\mathrm{Ce}$, La and $Y$ are plotted in Figure 1.

Results revealed that the organic phase, consisting of kerosene, V10 and TBP was highly efficient to extract up to the $100 \%$ of $\mathrm{La}$ and $\mathrm{Y}$ (Figure $1 \mathrm{~b}$ and $\mathrm{c}$, respectively) whereas for $\mathrm{Ce}$ the highest extraction percentage remained around $50 \%$ (Figure 1 a).

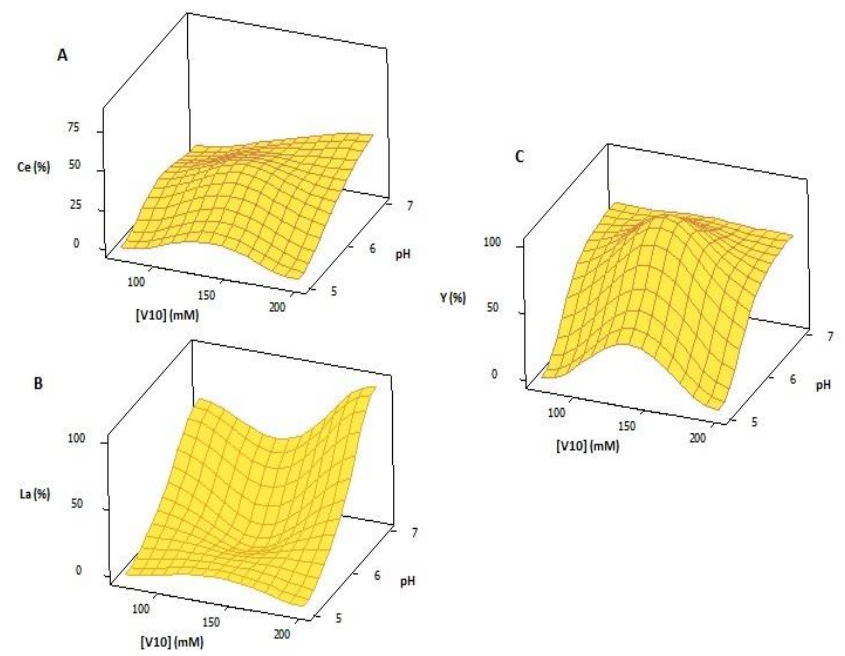

Figure 1. Surface plot for cerium (a), lanthanum (b) and yttrium extraction (c)

During the extraction step, a complexation mechanism occurs between REM ions and V10 which can be described as below:

$$
\mathrm{M}^{3+}+2(\mathrm{HR})_{2, \text { org }} \leftrightarrows\left(\mathrm{MR}_{3} \bullet(\mathrm{HR})\right)_{\text {org }}+3 \mathrm{H}^{+}
$$

where org subscript denotes the organic phase, $\mathrm{M}^{3+}$ represents the trivalent REM whereas $H R$ is the carrier. As V10 is an acidic carrier in forms of dimers in aliphatic solvents, it is aggregated as dimmers or larger oligomers in non-polar organic solvents (Mason et al., 1987).

The surface plot for Ce extraction versus $\mathrm{pH}$ and V10 (Figure 1a) shows that the highest efficiency took place when both variables were set in the corresponding middle level. This extraction behaviour is similar for $Y$, while for La the obtained surface plot displays a different pattern.

The typical extraction behaviour of the REMs lies in the increase in extraction efficiency with increase in the $\mathrm{pH}$, as broadly observed. The obtained results are in agreement with those reported in literature, in which the significant effect of $\mathrm{pH}$ on the extraction efficiency is contributed to the metal ions extraction as described in Eq. 2 (Feng et al., 2014).

After each run, the aqueous phase $\mathrm{pH}$ was measured, and the results showed a decrease in $\mathrm{pH}$ as soon as the extraction process took place (Table 3). Indeed, the uptake of metal ions decreases the $\mathrm{pH}$ of the aqueous feed phase (Agrawal et al., 2012; Babakhani et al., 2014; Noori et al.,
2014; Devi, 2015) as a result of an increase of $\left[\mathrm{H}^{+}\right]$ions in the aqueous feed phase, which is a side effect of the metalcarrier complexation in the feed-organic interface (Eq. 2).

Table 3. $\mathrm{pH}$ variation $(\Delta \mathrm{pH})$ in the aqueous phase for each run of the design of experiments

\begin{tabular}{ccccc}
\hline Run & $\mathbf{p H}$ & $\mathbf{V 1 0}(\mathbf{m M})$ & $\mathbf{T B P}(\mathbf{m M})$ & $\mathbf{\Delta} \mathbf{H}$ \\
\hline 1 & 5.0 & 200.0 & 50.0 & 0.35 \\
\hline 2 & 6.0 & 137.5 & 100.0 & 0.46 \\
\hline 3 & 7.0 & 200.0 & 150.0 & 0.54 \\
\hline 4 & 5.0 & 75.0 & 150.0 & 0.31 \\
\hline 5 & 7.0 & 75.0 & 50.0 & 0.47 \\
\hline 6 & 5.0 & 75.0 & 150.0 & 0.29 \\
\hline 7 & 7.0 & 75.0 & 50.0 & 0.50 \\
\hline 8 & 5.0 & 200.0 & 50.0 & 0.29 \\
\hline 9 & 5.0 & 75.0 & 150.0 & 0.31 \\
\hline 10 & 7.0 & 200.0 & 150.0 & 0.52 \\
\hline 11 & 7.0 & 75.0 & 50.0 & 0.41 \\
\hline 12 & 5.0 & 200.0 & 50.0 & 0.23 \\
\hline 13 & 7.0 & 200.0 & 150.0 & 0.57 \\
\hline
\end{tabular}

The extraction efficiency is affected by the solution $\mathrm{pH}$ as well as by the carrier concentration. This condition can be explained by applying the equilibrium constant ( $\left.K_{\text {eq }}\right)$ to Eq.2:

$$
\mathrm{K}_{\mathrm{eq}}=\left[\mathrm{MR}_{3}-\mathrm{RH}_{3}\right]_{\mathrm{org}}\left[\mathrm{H}^{+}\right]^{3} /\left[\mathrm{M}^{3+}\right][(\mathrm{HR})]^{2}
$$

The distribution ratio (D) relating to the aqueous/organic system is:

$$
\mathrm{D}=\left[\mathrm{M}^{n+}\right]_{o r g} /\left[\mathrm{M}^{n+}\right]_{a q}
$$

where $\left[\mathrm{M}^{\mathrm{n}+}\right]$ represents the concentration of metal ion and the subscripts org and $a q$ denote the organic and the aqueous phase, respectively.

Considering the metal concentration in the organic phase equal to metal-carrier complex concentration:

$$
\left[\mathrm{M}^{n+}\right]_{\text {org }}=\left[\mathrm{MR}_{3}-\mathrm{RH}_{3}\right]
$$

Substituting Eq. 3 and Eq. 4 into Eq. 5 and rearranging, the distribution ratio results equal to:

$$
\left.\mathrm{D}=\mathrm{K}_{\mathrm{eq}} \cdot\left[(\mathrm{HR})_{2}\right]^{2}\right\} /\left[\mathrm{H}^{+}\right]^{3}
$$

Taking logarithm of Eq. 6 it gives:

$$
\log D=\log K_{e q}+2 \log \left[(R H)_{2}\right]-3 \log \left[\mathrm{H}^{+}\right]
$$

Since $-\log [\mathrm{H}+]=\mathrm{pH}$, Eq. 8 can be written as:

$$
\log \mathrm{D}=\log \mathrm{K}_{\mathrm{eq}}+2 \log \left[(\mathrm{RH})_{2}\right]+3 \mathrm{pH}
$$

Eq. 8 explains how the metal extraction, in terms of distribution ratio, is a function of both carrier concentration and aqueous feed phase $\mathrm{pH}$.

Based on the estraction studies, $\mathrm{pH}$, carrier and phase modifier concentrations were set to 7, $200 \mathrm{mM}$ and $100 \mathrm{mM}$, respectively, for the further stripping studies.

\subsection{Stripping studies}

The chemical characterization of the white precipitate resulting from the stripping studies revealed that oxalic acid was capable of $100 \%$ stripping of the two targeted REMs, lanthanum and yttrium, from the organic phase whereas in case of cerium, no stripping efficiency was 
observed. At the end of the process, around 7.63 and 13.82 $\mathrm{mg} / \mathrm{Kg}$ of lanthanum and yttrium, respectively, were recovered.

Stripping process, which consists of the decomplexation of metal-carrier compounds and the subsequent complexation between the released metal ions and the stripping agent, follows the Eq. 2 in left to right direction. The use of oxalic acid causes the occurrence of stripping and precipitation simultaneously as it can act as both stripping and precipitation agent. Indeed, the oxalic acid dissociates in the aqueous phase in hydrogen ions and oxalate anions: the hydrogen ions provide the stripping of the rare earth ions present in the organic phase and the oxalate anions their precipitation in form of white powders (Konishi et al., 1998). Complexation between REM ions and oxalic acid $\left(\mathrm{H}_{2} \mathrm{C}_{2} \mathrm{O}_{4}\right)$ can be presented as follow:

$$
2 \mathrm{M}^{3+}+3 \mathrm{H}_{2} \mathrm{C}_{2} \mathrm{O}_{4} \leftrightarrows \mathrm{M}_{2}\left(\mathrm{C}_{2} \mathrm{O}_{4}\right)_{3}+6 \mathrm{H}^{+}
$$

where $\mathrm{M}^{3+}$ represents the trivalent REM (Chi and $\mathrm{Xu}$, 1999). Figure 2 shows the XRD pattern of the white precipitate.

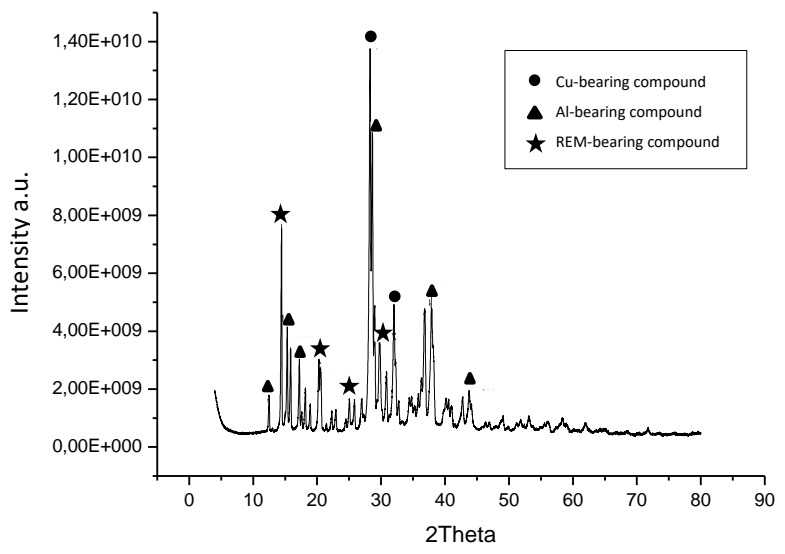

Figure 2. XRD pattern for the white precipitate

The mineral phase analysis confirmed the existence of rare earth compounds, mainly in the form of rare earth oxalates and oxides, although rare earth silicates and carbonates were found as well.

The occurrance of rare earth silicates is related to the presence of silicon dioxide in the WEEE dust source (Marra et al., 2018). The rare earth carbonate existence is due to the reaction of the oxalic acid with $\mathrm{Ca}$ and $\mathrm{Mg}$ ions in solution to form oxalates. Reported electro-kinetic measurements indicated that $\mathrm{Ca}^{2+}$ and $\mathrm{Mg}^{2+}$ cations actively reduce the negative charge at the pyrochlore surface hindering cationic collector adsorption (Rao et al., 1988; Chelgani et al., 2012 a, b; Xia et al., 2015). The higher concentration of oxalic acid might be a useful remedy to decrease the amount of rare earth-carbonate compounds. However, according to Chelgani et al. (2017), the acid addition could promote an increase in the rate of carbonate dissolution increasing the production of $\mathrm{Mg}$ and $\mathrm{Ca}$ in the solution.
However, both chemical characterization and mineral phase analysis pointed out that, apart from REMs, other metals ions including base metals and heavy metals (such as aluminium, cadmium, nickel, iron, copper and zinc) were co-stripped along with the REMs. The co-stripping of the metals ions is due to the simultaneously presence in WEEE shredding dust of a wide range of different metals, including base metals, in relative high concentrations (Marra et al., 2018). In this regard, a prevalence of alumina compounds was found (Figure 2), due to the high concentrations of aluminium detected in the WEEE shredding dust (Marra et al., 2018) as well as the strong chemical interaction existing between alumina and rare earth oxides (Bernal et al., 2005).

\section{Conclusions}

The solvent extraction of REMs from WEEE leaching solution using Versatic 10 as a carrier and TBP as phase modifier in kerosene was investigated. High efficiency in REM ion extraction was found. The results of a two-level factorial design revealed that high percentage of cerium, yttrium and lanthanum could be extracted at $\mathrm{pH} 7$, [V10] $200 \mathrm{mM}$ and [TBP] $100 \mathrm{mM}$. For the recovery of the leachate REMs from the organic phase, $750 \mathrm{mM}$ of oxalic acid showed $100 \%$ of the REM recovery, except for cerium. XRD analysis revealed that the recovered REMs mainly occurred in forms of REM oxalates, but silicate and carbonate rare earth compounds were even found, as well as other heavy metal-bearing compounds.

\section{Acknowledgements}

This work was partly funded by the FARB project of the University of Salerno (Italy). Authors wish to thank Dr Anna Farina for her valuable support in the analytical work. The authors would like to thank Universiti Sains Malaysia (Malaysia) for the financial support under Research University (RUI) Grant, No.: 1001/PTEKIND/814239.

\section{References}

Agrawal A., Pathak P., Mishra D. and Sahu K.K. (2012), Solvent mediated interactions for the selective recovery of Cadmium from Ni-Cd battery waste, Journal of Molecular Liquids, 173, 77-84.

Alonso E., Sherman A.M., Wallington T.J., Everson M.P., Field F.R., Roth R. and Kirchain R.E. (2012), Evaluating rare earth element availability: a case with revolutionary demand from clean technologies, Environmental Science \& Technology, 46, 3406-3414.

Armenta S., Garrigues S. and de la Guardia M. (2008), Green analytical chemistry. Trends in Analytical Chemistry, 27, 497511.

Babakhani A., Rashchi F., Zakeri A. and Vahidi E. (2014), Selective separation of nickel and cadmium from sulfate solutions of spent nickel-cadmium batteries using mixtures of D2EHPA and Cyanex 302, Journal of Power Sources, 247, 127-133.

Bakas I., Fischer C., Haselsteiner S., McKinnon D., Milios L., Harding A., Kosmol J., Plepys A., Tojo N., Wilts C.H. and Wittmer D. (2014), Present and Potential Future Recycling of Critical Metals in WEEE. Copenhagen Resource Institute (Eds.), Copenhagen. 
Baldé C.P., Wang F., Kuehr R. and Huisman J. (2015), The Global E-waste Monitor-2014. United Nations University, IAS-SCYCLE, Bonn.

Bernal S., Blanco G., Gatica J.M., Omil J.A.P., Pintado and Vidal H. (2005), Chemical reactivity of binary rare earth oxides, In: Binary Rare Earth Oxides, Adachi G., Imanaka N. and Kang Z.C. (Eds.), Kluwer Academic Publishers, USA.

Binnemans K., Jones P.T., Blanpain B., Van Gerven T., Yang Y. Walton A. and Buchert M. (2013), Recycling of rare earths: a critical review, Journal of Cleaner Production, 51, 1-22.

Buchert M., Manhart A., Bleher D. and Pingel D. (2012), Recycling Critical Raw Materials from Waste Electronic Equipment, Commissioned by the North Rhine-Westphalia State Agency for Nature, Environment and Consumer Protection, Darmstadt.

Bunus F., Miu I. and Dumitrescu D. (1994), Simultaneous recovery and separation of uranium and rare-earths from phosphoric acid in a one-cycle extraction stripping process, Hydrometallurgy, 35, 375-389.

Chagnes A., Courtaud B., Thiry J., Bayardon J., Jugé S. and Cote G. (2012), Influence of phase modifiers on the degradation of trin-octylamine/dodecane extracting mixture by an acidic solution of vanadium (V), Solvent Extraction and lon Exchange, 30, 67-76.

Chang S.H., Teng T.T. and Norli I. (2011), Optimization of Cu(II) extraction from aqueous solutions by soybean-oil-based organic solvent using response surface methodology, Water Air Soil Pollution, 217, 567-576.

Chelgani S.C. and Hart B. (2017), Explaining surface interactions for common associated gangues of rare earth minerals in response to the oxalic acid, International Journal of Mining Science and Technology, Article in Press.

Chelgani S.C., Hart B., Marois J. and Ourriban M. (2012a), Study of pyrochlore matrix composition effects on froth flotation by SEM-EDX, Mineral Engineering, 30, 62-6.

Chelgani S.C., Hart B., Marois J. and Ourriban M. (2012b), Study of pyrochlore surface chemistry effects on collector adsorption by TOF SIMS, Mineral Engineering, 39, 71-6.

Chi R. and Xu Z. (1999), A solution chemistry approach to the study of rare earth element precipitation by oxalic acid, Metallurgical and Materials Transactions B, 30, 189-195.

Devi N. (2015), Extraction of manganese (II) from acidic buffer medium using D2EHPA and Cyanex 272 as extractants, Journal of Chemical and Pharmaceutical Research, 7, 766-776.

Diaz L.A., Lister T.E., Parkman J. and Clark G. (2016), Comprehensive process for the recovery of value and critical materials from electronic waste, Journal of Cleaner Production, 125, 236-244.

Dupont D. and Binnemans K. (2015), Rare-earth recycling using a functionalized ionic liquid for the selective dissolution and revalorization of Y2O3:Eu3+ from lamp phosphor waste, Green Chemistry, 17, 2150-2163.

Feng X., Ting A.Z., Dreisinger D. and Doyle F. (2014). A critical review on solvent extraction of rare earths from aqueous solutions, Minerals Engineering, 56, 10-28.

Harris D.H. and Tompkins E.R. (1947), Ion-exchange as separations method. II. Separations of several rare earths of the cerium group ( $\mathrm{La}, \mathrm{Ce}, \mathrm{Pr}$ and $\mathrm{Nd}$ ) 1, Journal of the American Chemical Society, 69, 2792-2800.
Innocenzi V., De Michelis I., Kopacek B. and Vegliò F. (2014), Yttrium recovery from primary and secondary sources: A review of main hydrometallurgical processes, Waste Management, 34(7), 1237-1250.

Kang W., Jing G., Zhang H., Li M. and Wu Z. (2006), Influence of demulsifier on interfacial film between oil and water, Colloids and Surfaces A: Physicochemical and Engineering Aspects, 272, 27-31.

Keith L.H., Gron L.U. and Young J.L. (2007). Green analytical methodologies, Chemical Reviews, 107, 2695-2708.

Konishi Y., Noda Y. and Asai S. (1998). Precipitation Stripping of Yttrium Oxalate Powders from Yttrium-Loaded Carboxylate Solutions with Aqueous Oxalic Acid Solutions, Industrial \& Engineering Chemistry Research, 37, 2093-2098.

Kurniawan T.A., Gilbert Y.S., Chan G., Lo W. and Babel S. (2006), Physico-chemical treatment techniques for wastewater laden with heavy metals, Chemical Engineering Journal, 118, 83-98.

Lee G.S., M. Uchikoshi M., K. Mimura K. and Isshiki M. (2009), Distribution coefficients of $\mathrm{La}, \mathrm{Ce}, \mathrm{Pr}, \mathrm{Nd}$ and $\mathrm{Sm}$ on Cyanex 923-, D2EHPA-, PC 88A-impregnated resins, Separation and Purification Technology, 67, 79-85.

León G. and Guzmán M.A. (2010), Facilitated transport of cobalt through bulk liquid membranes containing D2EHPA as carrier. Kinetic study of the influence of some operational variables, Desalination and Water Treatment, 13, 267-273.

Marcus Y. (2004), Principles of solubility and solutions. In: Solvent Extraction Principles and Practice, Rydberg J., Cox M., Musikas and Choppin G.R. (Eds.), Marcel Dekker, New York.

Marra A., Cesaro A., Rene E.R., Belgiorno V. and Lens P.N.L. (2018), Bioleaching of metals from WEEE shredding dust. Journal of Environmental Management, 210, 180-190.

Mason G.W., Bilobron I. and Peppard D.F. (1987). Extraction of $\mathrm{U}(\mathrm{VI}), \mathrm{Th},(\mathrm{IV}), \mathrm{Am}$ (III) and Eu(III) by bis para-octyl phosphoric acid in benzene diluent, Journal of Inorganic and Nuclear Chemistry, 40, 1807-1810.

Muthuraman G., Teng T.T., Leh C.P. and Norli I. (2009), Extraction and recovery of methylene blue from industrial wastewater using benzoic acid as and extractant, Journal of Hazardous Materials, 163, 363-369.

Noori M., Rashchi F., Babakhani A. and Vahidi E. (2014), Selective recovery and separation of nickel and vanadium in sulfate media using mixtures of D2EHPA and Cyanex 272. Separation and Purification Technology, 136, 265-273.

Preston J.S., Cole P.M., Du Preez A.C., Fox M.H. and Fleming A.M. (1996), The recovery of rare earth oxide from a phosphoric acid by-product. Part 2 . The preparation of high purity cerium dioxide and recovery of heavy rare earth concentrate, Hydrometallurgy, 41, 21-44.

Rao S.R., Gomez R.E., Finch J.A. and Biss R. (1988), Effects of water chemistry on the flotation of pyrochlore and silicate minerals, Mineral Engineering, 1, 189-202.

Savvilotidou V., Hahladakis J. and Gidarakos E. (2015), Leaching capacity of metals-metalloids and recovery of valuable materials from waste LCDs, Waste Management, 45, 314-324.

Singh R., Mehta R. and Kumar V. (2011), Simultaneous removal of copper, nickel and zinc metal ions using bulk liquid membrane system, Desalination, 272, 170-173.

Talebi A., Teng T.T., Alkarkhi A.F.M., Norli I. and Low L.L. (2012), Optimization of nickel removal using liquid-liquid extraction 
and response surface methodology. Desalination and Water Treatment, 47, 334-3340.

Tanushree D., Ki-Hyun K., Minori U., Eilhann E.K., Byong-Hun J., Akash D. and Seong-Taek Y. (2016), Global demand for rare earth resources and strategies for green mining: Review article, Environmental Research, 150, 182-190.

Tunsu C. and Retegan T. (2016), Hydrometallurgical processes for the recovery of metals from WEEE, WEEE Recycling: Research, Development, and Policies, 139-175.

Tunsu C., Petranikova M., Gergorić M., Ekberg C. and Retegan T. (2015). Reclaiming rare earth elements from end-of-life products: A review of the perspectives for urban mining using hydrometallurgical unit operations, Hydrometallurgy, 156, 239-258.

Xia L., Hart B. and Douglas K. (2015), The role of citric acid in the flotation separation of rare earth from the silicates. Mineral Engineering, 74, 123-9. 